\title{
Çin Propagandasında Çin-Tayvan İliş̧kilerinin Sunumu: Mao Zedong Dönemi Üzerine İnceleme
}

\author{
Caner ÇAKI*, Yusuf FIDAN**
}

Öz

1949 yılında Çin Komünist Partisi (ÇKP) lideri Mao Zedong, Çin Milliyetçi Partisi (Kuomintang) lideri Çan Kay Şek'i kesin olarak yenilgiye uğratmıştı. Mao, ülkenin yönetimini ele geçirmiş, Şek ise Tayvan adasına kaçarak yönetimini burada sürdürmüştü. Bu tarihten itibaren Çin ve Tayvan arasında düşmanlık dönemi başlamıștır. Bu aşamada Mao yönetimi, Çin kamuoyunda Tayvan'a karşı yoğun bir propaganda faaliyetine yönelerek, Tayvan'ı düşman bir ülke olarak yansıtmıștı. Çin yönetiminin Tayvan karşıtı faaliyetlerinde en sık kullandığı kitle iletişim araçlarından birisi posterler olmuştu. Bu çalışmada Çin propagandası tarafından Tayvan'a karşı kullanılan posterlerde, Tayvan'ın nasıl ve ne şekilde sunulduğu ortaya konulmaya çalıșılmıştır. Bu amaçla çalışma kapsamında Şanghay Propaganda Posterleri Sanat Müzesi'nden belirlenen altı propaganda posteri, nitel araştırma yöntemleri içerisinde yer alan göstergebilimsel analiz yöntemi kullanılarak incelenmiştir. Çalışmada belirlenen Çin propaganda posterleri, Fransız dilbilimci Roland Barthes'ın göstergebilim anlayışı üzerinden ele alınmıștır. Çalışmada ele edilen bulgularda Çin propagandası tarafından Tayvan'a yönelik doğrudan nefret söylemi oluşturulduğu ortaya çıkarılmıştır. Diğer yandan Çin propagandası posterler üzerinden Mao'nun ölümüne dek Çin'in Tayvan'ı ele geçireceği mesajını verdiği, bu yolla iki ülke arasındaki düşmanlığı canlı tutmaya çalıştığı sonucuna ulaşılmıştır.

Anahtar Kelimeler: Çin, Tayvan, Propaganda, Mao Zedong, Göstergebilim

\section{The Presentation of Chinese-Taiwan Relations in The Chinese Propaganda: Examination on Mao Zedong Period}

\begin{abstract}
The leader of Chinese Communist Party (CCP) Mao Zedong defeated the leader of Chinese Nationalist Party (Kuomintang) Chiang Kai-Shek in 1949. Mao seized the control of country and Shek escaped to Taiwan. From that time, the period of enmity between China and Taiwan began. At this stage, the Mao administration showed the Taiwanese as a hostile country, focusing on an intense propaganda campaign in the Chinese public opinion. One of the mass media tools used by the Chinese administration in anti-Taiwan propaganda was posters. In this study, it was tried to show how and in what way Taiwan

\section{Özgün Araștırma Makalesi (Original Research Article) \\ Geliș/Received: 05.04.2019 \\ Kabul/Accepted: 02.07.2019 \\ DOI: https://dx.doi.org/10.17336/igusbd.549639}

*Arş. Gör., İnönü Üniversitesi, İletişim Fakültesi, İletişim Bilimleri Bölümü, Malatya, Türkiye,

E-posta: caner.caki@inonu.edu.tr ORCID ID https://orcid.org/0000-0002-1523-4649

** Arș. Gör., Nevșehir Hacı Bektaș Veli Üniversitesi, İktisadi ve İdari Bilimler Fakültesi, Uluslararası

İlişkiler Bölümü, Nevșehir, Türkiye, E-posta: ysfdn90@hotmail.com

ORCID ID https://orcid.org/0000-0003-4975-5845
\end{abstract}


was presented in posters used by China propaganda against Taiwan. For this purpose, six propaganda posters determined from the Shanghai Propaganda Posters Art Museum were examined using semiotic analysis in qualitative research methods. The Chinese propaganda posters, determined in the study, were analyzed in terms of the semiotical concepts of the French linguist Roland Barthes. The findings of the study revealed that there was a hate speech against Taiwan in Chinese propaganda. On the other hand, it was concluded that Chinese propaganda gave the message that China would conquer Taiwan until Mao's death, continuing the enmity between the two countries through the posters.

Keywords: China, Taiwan, Propaganda, Mao Zedong, Semiotics

\section{Giriş}

Çin İç Savașı (1927-1950), dünya tarihinin en kanlı iç savaşlarından biri olmuştur. Mao Zedong liderliğindeki Çin Komünist Partisi (ÇKP), Çin'i yöneten Çan Kay Şek liderliğindeki Çin Milliyetçi Partisi'ne (Kuomintang) karşı başlattığı isyan sonucunda, 1949 yılında Tayvan ve bir kaç küçük ada dışında Çin'in tamamı ele geçirmeyi başarmıştı. Çan Kay Şek, Mao karşısında aldığı yenilgiden sonra Tayvan'a kaçmış ve Çin Cumhuriyeti'nin Tayvan'da devam ettiğini ilan etmişti. Mao ülkede kontrolü tamamen sağladıktan sonra 1 Ekim 1949 yılında Çin Halk Cumhuriyeti'nin (ÇHC) kurulduğunu ilan etmişti. ÇHC, kurulduğu ilk günden itibaren Tayvan'ın varlığını, ülkenin geleceği için en büyük tehlike olarak görmeye başlamıştı. Amerika Birleşik Devletleri'nin Tayvan'a doğrudan destek vermesi, ÇHC'nin Tayvan'ı işgal etmesine mani olmuştu. Bu aşamada ÇHC, Mao'nun iktidarı döneminde (1949-1976) Tayvan'a yönelik doğrudan nefret söylemi içeren propaganda faaliyetlerine yönelmiști. Tayvan'a karşı girişilen Çin propagandanın temelinde, Çin halkının Kuomintang'ın milliyetçi söylemlerinin etkisi altında kalmasının engellenmesi ve ulusal bilincin uyandırılmasında Çan Kay Şek yönetiminin düşman unsur olarak gösterilmesi yatmaktaydı. Bu amaçla dönemin en etkili kitle iletişim araçlarından biri olan posterler, Tayvan karşıtı Çin propagandası tarafından etkili bir biçimde kullanılmıştı. Çalışmada Tayvan karşıtı hazırlanan Çin propaganda posterleri, göstergebilimsel analiz yöntemi kullanılarak incelenmiştir.

Alanda yapılan kapsamlı literatür taraması sonucunda, Çin propaganda faaliyetlerini inceleyen alanda bazı çalışmalara rastlanmıștır. Bunlar içerisinde; Edney (2014), Çin tarafından yürütülen ulusal ve uluslararası faaliyetlerini incelemiştir. Weber (2002), televizyon üzerinden yürütülen Çin propagandasını analiz etmiştir. Powell ve Wong (1997), Çin Kültür Devrimi sırasında kullanılan propaganda posterleri üzerine araștırmada bulunmuştur. Johnson (2012), Çin sinemasında propaganda ve sansürü ele almıştır. Chen (2003), ÇKP'nin propaganda amaçlı filmleri üzerine incelemede bulunmuştur. Brady ve Juntao (2009), ÇKP'nin iktidarını güçlendirmede propagandadan nasıl yararlanıldığını açıklamaya çalıșmıștır. Zhang ve Cameron (2004), Çin propagandasındaki yapısal dönüşüm üzerine analiz yapmıștır. Chen (2016), Çin propagandasında tiyatro ve sinema üzerine incelemede bulunmuştur. Diğer yandan son yıllarda Türkiye'de göstergebilimsel analiz yönteminden yararlanılarak farklı dönemlerde kullanılan propaganda posterlerini inceleyen alanda önemli akademik çalışmaların yapıldığı görülmektedir. Bunlar içerisinde; Çakı (2018a), Sovyet lider Joseph Stalin iktidarında Ermenistan'da kullanılan propaganda posterlerini göstergebilimsel açıdan analiz etmiștir. Yine Çakı (2018b), İran İslam Cumhuriyeti lideri Ruhullah Humeyni döneminde gerçekleşen İran-Irak Savaşı'nda kullanılan İran propaganda posterlerini incelemiştir. Benzer şekilde Çetin vd. (2018), Humeyi döneminde ABD karşıtı olarak hazırlanan İran propaganda posterlerini incelemiștir. Gazi vd. (2018a), Stalin döneminde Sovyetler Birliği'nde kullanılan propaganda posterlerinde Stalin'in kült lider olarak nasıl 
inşa edildiğini incelemiştir. Son olarak Çakı (2018c), Nazi Almanyası lideri Adolf Hitler döneminde kullanılan propaganda posterlerinde Hitler'in kült lider olarak nasıl ve ne şekilde inşa edilmeye çalışıldığını ele almıștır.

Literatür taraması sonucunda Çin-Tayvan ilişkileri özelinde Çin propagandasını inceleyen bir çalıșmaya rastlanılamamıștır. Çalışma kapsamında ise Mao dönemi özelinde Tayvan karşıtı Çin propaganda posterleri ele alınmıştır. Çalışmada, "Mao Zedong döneminde kullanılan Tayvan karşıtı Çin propaganda posterlerinde Tayvan yönetimi nasıl ve ne şekilde sunulmaktadır" sorusu üzerinden incelemede bulunulmuştur. Bu amaçla posterlerde hangi görsel ve yazılı kodlar kullanıldığı, Tayvan'a yönelik hangi propaganda mitlerinin inșa edildiği, hangi vaatlerde bulunulduğu çalışma kapsamında incelenmiștir.

\section{Çin İç Savaşı'na Genel Bakış}

1927 yılında bașlayıp 1950 yılında sona eren ancak tarafların zaman zaman dıș ve iç tehditlere karşı birleştiği Çin İ ç Savaşı, Çin tarihinde çok önemli değişimleri beraberinde getirmiştir. Çin Milliyetçi Partisi (Kuomintag) ile Çin Komünist Partisi (ÇKP) arasında yaşanan çatışmalar, yüz binlerce insanın ölümüne ve Çin'in sosyal, siyasal ve ekonomik yapısında köklü değişimlere yol açmıştır. 1905 Rus-Japon Savaşı, Rusya'da 1917 yılında yaşanan Ekim Devrimi, komünizmin yayılma politikası, Japonya'nın Mançurya'yı ve Tayvan'ı işgali ve Çin'e yönelik saldırgan tutumu, Batılıların Çin'i sömürme planları ve politikaları, İkinci Dünya Savașı'na giden sürecin doğurduğu gelişmeler ve Japonya ile ABD’nin bu savașta karșı karşıya gelmesi gibi dıș unsur ve dinamikler de bir şekilde Çin İç Savaşı'na etki etmiștir.

Çin, 20. yüzyıla kadar Qing Hanedanlığ11tarafından yönetilmiştir. Buna karşın 20. yüzyılın başında ülkede reform çağrıları yükselmeye başlamıștır. Reform çağrılarının yanında Batı karşıtı söylemlerin de güçlendiği görülmüștür. Nitekim, 1900 yılında Batı karşıtı bır hareket olan ve ülkedeki tüm yabancıların Çin'den atılmasını savunan Boxer İsyanı meydana gelmiștir. Yașanan bu gelişmeler Qing Hanedanlı̆̆ı'nın sonunu getiren 1911 Devrimi'ne önayak olmuştur. Bu süreçte isyancılar, Qing İmparatoru'nu ele geçirmiş ve Yuan Shikra'yı lider olarak seçmiştir (Lynch, 2016: 271-272). Qing Hanedanlığı'nın sona ermesiyle, Çin'de savaş lordları tarafından kontrol edilen küçük devletçikler ortaya çıkmıştır. "Milletin babası" olarak adlandırılan Sun Yat-Sen isimli devlet adamı Çin'in bu kaotik durumundan rahatsızlık duymuş ve Çin'i bir çatı altında toplamak istemiştir (Lynch, 2010: 17). Sun Yat-Sen, sürgünde olduğu Japonya'da ilk ismi "Çin Devrimci Partisi" olan "Çin Milliyetçi Partisi"ni kurmuştur (Lynch, 2010: 26; Elleman, 2001: 149). Geçici olarak Nanjing'te kurulan hükümet, Güney Çin ile sınırlı kalmıştır (Lynch, 2010: 26).

Aralık 1912'de Çin Cumhuriyeti'nde düzenlenen parlamento seçimleri, Kuomintag'ın üstünlügü ile neticelenmiştir (Ropp, 2010: 115). Buna karşı ÇKP, ülkenin yönetimini tamamen elinde tutmayı başaramamıştır (Pong, 2009: 134). İlerleyen süreçte Sun-Yat Sen Çin'e geri dönmüş ve Kuomintang'ın liderliğini almıştır. 1917 Bolşevik Devrimi, Çin için geri kalmış fakir bir ülkenin Marksist hareket ile güç kazanabileceğini, hızlı bir modernleșme sağlayabileceğini ve güçlü, zengin ve bağımsız bir ulusun inşa edilebileceğini ortaya koymuştur (Ropp, 2010: 119). Çin'in yeniden yapılandırılması ve Çin'i tek bir çatı altında toplamak için Sovyetler Birliği'nden destek aranmıştır (Ropp, 2010: 120). Bu çerçevede, Sovyet destekli Uluslararası Komünist oluşum olan Komintern ile görüşmelere başlamıştır (Elleman, 2001: 150). Komintern, Sun'ın milliyetçi Kuomintag

\footnotetext{
${ }^{1}$ Ayrıca Manchu Hanedanlığı olarak da bilinen Çin'in son hanedanlığı, 1644-1911 yılları arasında Çin'i yönetmiştir (Lynch, 2010, 2).
} 
partisinin ittifaka katılması halinde Komintern'in Çin'de yeni kurulmuş olan Komünist Parti (CPC/CCP)2 ${ }^{2}$ ile birlikte Kuomintag'a mali, askeri ve politik yardımlarda bulunacağ sözünü vermiştir (Lynch,2016: 74). Kuomintang, ÇKP ile de 1922 yllında ittifak kurmuştur (Mortonand ve Lewis, 2005: 185-187). Çin'in tek bir çatı altında toplanması, Kuomintang lideri Sun'ın 1925 yılında ölmesi sonucu sekteye uğramıștır. Sun'dan sonra Çan Kay Şek, Kuomintang liderliğini devralmıștır. Çan Kay Şek, Sun'ın aksine ÇKP ile ittifaka sıcak bakmamıştır (Cheek, 2008: 11).

Çan Kay Şek, yönetime gelir gelmez Komünistlere karşı saldırgan bir politika izlemiștir. Bu süreç komünist liderler Lee Sung ve Mao Zedong'un Komitang'a karşı gerilla savaşı başlatmasına yol açmıștır (Elleman, 2001: 217). Mao'nun bu süreçte parti içinde ağırlı̆̆ı hissedilmeye başlanmıştır (Lynch, 2010: 62). 1927'de. Çan Kay Şek, ÇKP ile ittifakı bozmuş ve "Beyaz Terör"3 olarak nitelendirilen Şangay Katliamı ile Şangay'daki komünistleri katletmiştir. Binlerce Komünist, ticaret birlikleri ve köylü liderleri, Çin siyasetinden tasfiye edilmek amaciyla katledilmiştir (Lynch, 2010: 60-62). Bu süreçte Mao, komünistlerin şehirlerden ziyade kırsalda konuşlanmasının daha uygun olacağını planlamıștır.

1930 yllına gelindiğinde, Sovyetler Birliği, Çin ile daha yakından ilgilenmeye başlamıştır. 1929 Ekonomik Buhranı'ndan sonra komünizm ideolojisi dünya çapında güç kazanmıştı. Bu bağlamda, komünist oluşum olan Komintern Örgütü, komünizmin dünya çapında yayılmasını sağlamak için Çin'i ilk adım olarak görmüştür (Wasserstrom, 2016: 129). Diğer yandan Çan Kay Şek yönetimi, Japonya'nın Mançurya'yı ilhak etmesini önleyemedi. Japonya, Mançurya'yı işgal ettikten sonra burada Mançuko isminde bir kukla devlet kurmuștu (Eröktem, 2018: 5; Adshead, 2000: 316). Çan Kay Şek'in ordusu, Mao'nun birliklerine saldırması üzerine, komünistler Uzun Yürüyüş olarak da bilinen geri çekilme ile Çin'in kuzeyinde mevzilendi (Brooman, 1998: 12-13; Spence, 2012: 376).

Mao, 1935'te ÇKP'nin lideri olmuştu. Komünistler, Mao önderliğinde ilerleyen yıllarda yeniden toparlanmayı başarmıştır. Mao, Çan Kay Şek'in ordusuna karşı gerilla taktiğini uygulamıştır. Buna karşın Çan Kay Şek, Japonya'ya karşı komünistlerle ortak bir kuvvet olan "İkinci Birleșik Cephe'yi” kabul etmek zorunda kalmıștı. Çan Kay Şek, İkinci Dünya Savaşı'nda ABD’nin Japonya'nın ile mücadelesi sürecinde, Japonya'nın ABD tarafından yenilmesini beklemiştir. Bu süreç Çan Kay Şek'in kamuoyu nezdinde saygınlığını yitirmesine yol açmıştı (Gay, 2008: 40-41). İkinci Dünya Savaşı'nda Japonya, Müttefik Devletleri'ne karşı yenilgiye uğramış ve işgali altında bulunan Çin'den çekilmek zorunda kalmıştır. Bunun üzerinde Çan Kay Şek ile Mao Ağustos 1945 'te galibiyeti kutlamak için buluşmuş ve iki taraf da sonraki dönemde ülkenin inşası için mücadele edeceğini vurgulamıştır. Ancak, bu süreç beklenildiğinin aksine iki taraf arasında yeni bir çatışma oluşturmuştur (Eröktem, 2018: 6). Mançurya üzerinden savaşın sürdüğü Mançurya'da Kuomintang darbe almıştır. 1948'de Mançurya komünistler tarafından ele geçirilmiştir. 1949'da Tianjin, Pekin ve Çin'in kuzeyinin tamamı da komünistlerin kontrolü altına girmiştir (Ropp, 2010: 131-133). 1950 yılında iç savaş Kuomintang'ın yenilgisi ile son bulmuştur.

\footnotetext{
${ }^{2}$ Çin Komünist Partisi bazı öğrencilerin hükümete karşı protesto gösterilerinin vuku bulduğu 4 Mayıs Hareketi'nin ardından Temmuz 1921'de Şangay'da kurulmuștur (Daweiand Yanjing, 2011, 184).

${ }^{3}$ Burada kullanılan "beyaz" söylemi Chiang'ın milliyetçileri için kullanılmaktadır, öte yandan Komünistler ise "kzzl" olarak nitelendirilmektedir (Lynch, 2010, 60).
} 


\section{Mao Zedong İktidarı'nda Çin Halk Cumhuriyeti ve Tayvan İlişkileri}

1 Ekim 1949 tarihinde Mao, Çin Halk Cumhuriyeti'nin (ÇHC) kuruluşunu ilan etmiş̦tir. Çan Kay Şek'in ordusu, meclis üyeleri ve iş adamlarından oluşan yaklaşık iki milyon kişi Kuomintang'ın anakarada kontrolü kaybetmesi üzerine bașkent Nanking'ten Tayvan Adası'nda bir şehir olan Taipe'ye çekilmiştir (Mcmahon, 2013: 58-59). Çan Kay Şek, sözde Çin Cumhuriyeti'nin başkanlığına devam etmiş ve Çin'in egemenliğinde hak iddia etmeye devam etmiştir.

Çin İç Savașı'ndan zaferle çıkan Mao ve ÇKP, yeni problemlerle karşı karşıya kalmıștır. Çan Kay Şek ve Kuomintang rejimi, Çin'in güney sahili olan Tayvan Adası'nda ${ }^{4}$ konuşlanmıştır (Cheek, 2008: 18). ÇHC'nin, Tayvan ile ilișkisi pek sıcak olmamıştır. Nitekim Çan Kay Şek'in anakarayı geri alma, Mao'nun ise Tayvan ve yakınındaki adaları alma arzuları iki taraf arasında diyalog kurmayı engellemiștir. Taraflar zaman zaman sıcak çatıșmanın eșiğine de gelmiștir. İkili ilişkiler, genelde üçüncü taraflar aracıllğıyla adeta "vekil ilişki" șeklinde gerçekleșmiștir.

1954 yılında ÇHC'nin, Tayvan'a ait Qumoy ve Matsu adalarını bombalaması, taraflar arasında yeni bir çatıșmanın meydana gelmesi olasılığını işaret etmiștir. Bu bombardıman, 1955 Bandung Konferansı'na kadar devam etmiștir. Bandung'ta aşırı tepkiyle karşılaşan Mao hükümeti, bombardımanı sona erdirmiştir. ÇHC'nin bu saldırgan tutumunun ardından, ABD devreye girmiş ve Tayvan'ın hamiliğine soyunmuștur. Komünizmin Asya'da yayılmasının önüne geçmek isteyen ABD ile Tayvan arasında "Karşılıklı Savunma Anlaşması" imzalanmıştır. Bu anlaşmaya göre, Tayvan'ın siyasi istikrara yönelik tehditlere karşı ABD’nin, askeri güç olarak bölgeye konuşlanacağı vurgusu yapılmıştır (Eröktem, 2018: 8).

ÇHC ordusunun 1958 yılında Tayvan'a bağlı adaları yeniden bombalamaya başlaması üzerine yeni bir siyasi kriz ortaya çıkmıștır. ABD’nin aktif askeri önlem ve diplomatik girișimleri sonucu, ÇHC, bombardımanın şiddetini azaltacağını beyan etmiştir. Ardından da taraflar birbirlerine propaganda broșürleri atmaya başlamıștır (Eröktem, 2018: 8). Kuomintang'ın anakaradan Tayvan'a çekilmesinden sonra Tayvan'da düzenlenen siyasi seçimlerin üçünü de Çan Kay Şek kazanmıştır. Soğuk Savaş Dönemi'ne tekabül eden bu dönemde Çan Kay Şek, komünizme ve Sovyetler Birliği'ne karşı ABD’nin yanında yer almıștır. ABD’nin de Tayvan'ın koruyuculuğunu üstlendiği bu dönemde, Tayvan ekonomisi kayda değer bir gelișme göstermiștir. Tayvan'ın 1960'lardaki ekonomisi, oldukça önemli merhale kat etmiș ve bu durum ekonomik mucize olarak nitelendirilmiştir. Tayvan'daki bu kapitalist gelişim, modern bir işçi sınıfının ortaya çıkmasına yol açmıştır. Bütün bu gelişmeler, Tayvan'da Kuomintang'ın otoriter tutumunun eleştirilmesine ve demokratikleşme baskılarına yol açmıștır (Yalvaç, 2018: 205). Aynı dönemde Mao yönetimindeki ÇHC ise giderek otoriterleşmiş ve Tayvan'ın aksine ekonomik sorunlarla karşı karşıya kalmıştır. Öte yandan ÇHC, hiçbir zaman Tayvan'ın bağımsızlığı fikrini kabul etmemiş, adanın kendilerine ait olduğunu savunmuştur. Hatta Tayvan'ın bağımsızlığı, bitmemiş bir ulus-devlet projesinin bir parçası olarak görülmüștür (Eröktem, 2018, 7).

Soğuk Savaş Dönemi'nde Mao'nun ABD ile yürüttüğü ilişkiler, bir şekilde Tayvan ile olan ilişkileri de etkilemiş ve şekillendirmiştir. İlk olarak 1971 yılında ABD Dışişleri Bakanı Henry Kissinger ile yapılan gizli görüșmeler, daha sonra da 1972 yılında dönemin ABD Başkanı Nixon'ın Çin ziyareti, ikili ilişkileri tersine çevirmiştir. Zamanla ABD-ÇHC arasında karşılıklı olumlu ilişkiler gelişmiștir (Chai, 2002: 135). Hatta Çin daha önce

\footnotetext{
${ }^{4}$ Qing Hanedanlığı'nın hüküm sürdüğü ada, 1895'te Japonya tarafından işgal edilmiştir. Japonya'nın İkinci Dünya Savaşı'nda mağlup olması üzerine ise Çin’e bırakılmıştır (Rwei-ren 2004: 17).
} 
BM'de Tayvan tarafından temsil edilirken, ABD'nin desteğiyle ÇHC tarafından temsil edilmeye başlanmıştır (Cheek, 2008: 27-28).

ABD, bu dönemde ÇHC'nin Tayvan'dan daha stratejik önemde olduğuna kanaat getirmiştir. Bu yüzden, iki taraf arasında gerçekleşen 1972 yılındaki anlaşmada, Tayvan'ın en önemli destekçisi ABD, Tayvan'ın Çin'e bağlı olduğunu kabul etmiștir. Dahası ABD, Tayvan'da bulunan ordusunu geri çekeceğini de bildirmiştir (Kan, 2014: 35-36).

Tek Çin politikasında ısrarcı olan ve bu konuda ABD ile ilişkilerin gelişmesi ile birlikte eli kuvvetlenen Mao, Tayvan ile ÇHC arasındaki ilişkiler konusunda şunları söylemiştir; "Tayvan ile ilgili sorulara gelince, bu oldukça karmaşık. Barışçıl bir geçiş olabileceğini sanmıyorum. Onlar bir takım karşı devrimci (Tayvan'daki Milliyetçiler). Onlar bizimle nasıl işbirliği yapabilirler? Ben Şu an için bunu Tayvansız da yapabileceğimizi söylüyorum ve haydi bunu 100 yıl sonra gerçekleștirmiș olalım" (Kan, 2014: 37). Kuomintang lideri Çan Kay Şek, 1975 yılında ölmüştür. Çan Kay Şek’ten sonra Çan Kay Șek'in bașbakan olan oğlu Chiang Ching-Kuo cumhurbaşkanlığını devralmıștır. $\mathrm{Bu}$ değișim sonrasında oğul Çan Kay Şek anakaraya karşı daha yumuşak ve ılımlı bir politika izlemiştir (Eröktem, 2018: 10). Buna karşın Çin ve Tayvan ilişkilerindeki gerilimin günümüzde de sürdüğü söylenebilmektedir (Ling vd., 2009: 33).

\section{Metodoloji}

Çalışmada Mao döneminde Çin propagandası tarafından Tayvan'a karşı kullanılan posterler üzerinden dönemin propaganda faaliyetlerine ve Çin-Tayvan ilişkilerine işık tutulması çalışmanın temel amacını oluşturmaktadır. Böylece Çin-Tayvan ilişkilerinin günümüzdeki durumunun șekillenmesinde Mao dönemindeki Çin propagandasının nasıl bir rol oynadığının da ortaya konulması amaçlanmıştır.

Çalışma, ulusal alanda Çin-Tayvan ilişkilerinde propaganda faaliyetlerinin rolünü ele alan herhangi bir çalışmaya rastlanılamamış olması, uluslararası ilişkilerde propagandanın kullanımı hakkında örnek oluşturması, Mao dönemdeki Tayvan karşıtı Çin propagandası hakkında bilgi vermesi bakımından önem taşımaktadır.

Mao döneminde Tayvan'a karşı hazırlanan tüm propaganda posterleri çalışmanın evrenini oluşturmaktadır. Buna karşın çalışma kapsamında tüm propaganda posterlerine ulaşmanın güçlüğünden dolayı çalışmada amaçlı örneklem metodu kullanılarak belirlenen altı propaganda posteri üzerinden analiz yapılmıștır.

Çalışma kapsamında analizlerin yalnızca altı Çin propaganda posteri üzerinden yürütülmesi ve elde edilen bulgular kapsamında genellemelerde bulunulması çalışmanın temel sınırlılığını oluşturmaktadır.

Çalışmada nitel araştırma yöntemlerinde yer alan göstergebilimsel analiz metodu kullanılmıștır. Çin propagandası tarafından kullanılan propaganda posterleri Fransız dilbilimci Roland Barthes'ın göstergebilim anlayışı ışığında analiz edilmiştir.

Gösterge, belirli bir kavramın başka bir kavramın yerine kullanılmasını ve ona yönelik belli bir imajı oluşturmasını ifade etmektedir. Göstergebilim ise insanların belirli bir uzlaşı içerisinde oluşturdukları anlamlandırmaları inceleyen bir bilim dalıdır (Rifat, 2013: 99). Göstergebilim alanındaki ilk çalışmalar 20. yüzyılın başlarında ortaya çıkmıştır. $\mathrm{Bu}$ çalışmalar dilbilimciler Charles Sanders Peirce (1839-1914) ve Ferdinand de Sausssure'ün (1857-1913) birbirlerinden habersiz olarak yaptığı dilbilimi çalışmaları ile temellenmektedir. Her iki dilbilimci de çalışmaları ile göstergebilimin bir bilim dalı halini almasına ve günümüzde sık kullanılan sosyal bilimler araștırma yöntemlerinden biri haline gelmesine yol açmıştır (Gazi vd., 2018b: 15). Saussure toplumlar arasında dildeki anlamların farklılaşabileceğine vurgu yapmaktadır (De Saussure, 2014: 63). Bu süreçte Saussure'ün, göstergeleri, gösteren ve gösterilen düzleminde incelediği Göstergeler Modeli ön plana çıkmıștır. Bu modelde gösteren, gösterenin evrensel anlamını; gösterilen 
ise öznel anlamını içermektedir. Örneğin, bir gülün gösteren açıdan çiçeği ve gösterilen boyutta da aşkı ifade etmesi. Göstergebilim, ilk ortaya çıktığında göstergebilimin dilbilimi içerisinde bir alan olduğu düşünülmekteydi. Fakat daha sonra göstergebilim alanında yapılan çalıșmalar, dilbiliminin göstergebilimin bir parçası olduğunu göstermişti.

20.yüzyılın ikinci yarısında Fransız dilbilimci Roland Barthes (1915-1980), göstergebilimin, reklam, sinema, müzik gibi farklı disiplinleri inceleyen bir bilim dalı haline getirilmesinde önemli bir rol üstlenmiștir. Bu süreçte Saussure'ün etkisinde kalan Barthes, Saussure'ün ortaya koyduğu gösteren ve gösterilen kavramlarının yanında düzanlam ve yananlam kavramını da kullanmıştır. Düzanlam, gösterge veya göstergeler dizgesinin herkes tarafından kabul edilen, değișmeyen anlamlandırmalarını ifade etmektedir (Barthes, 2016a: 85). Yananlam ise kültürden kültüre değișen anlamları ifade edebilmektedir (Barthes, 2016b: 19). Yananlamların çözümlenmesi sürecinde, kültürel kodların doğru bir şekilde okunması gerekmektedir (Tanyeri Mazıcı ve Çakı, 2018: 295). Barthes, kültür içerisinde gerçekliklerin nasıl inşa edildiği üzerinde durmaktadır (Barthes, 2014: 63). Barthes, yananlamların şekillenmesinde mit kavramının üzerinde durmuştur. Göstergebilim boyutunda mit, insanların çevrelerinde yaşanan değişimleri ve gerçeklikleri açıklamak üzere oluşturdukları hikâyeleri ifade etmektedir. Mitler toplumda doğal bir süreçte kendiliğinden oluşabildiği gibi egemen güçler tarafından belirli ideolojik söylemlerin hâkim kılınabilmesi için de yapay olarak da inşa edilebilmektedir (Barthes, 2017: 18). Bu süreçte Barthes, kitle iletişim araçlarının yapay mitlerin inşasında önemli bir rol oynadığını söylemektedir. Egemen güçlerin denetimleri altında tuttukları kitle iletişim araçları yoluyla insanların günlük hayatta nasıl davranması gerektiğine kadar pek çok konuda etkili olabildiğini savunmuştur.

Çalışma kapsamında incelenen Çin propaganda posterleri üzerinden hangi yananlamların ortaya konulduğu ve hangi propaganda mitlerinin inşa edilmeye çalışıldığı ortaya konulmaya çalışılmıştır.

\section{Analiz}

Çalışma kapsamında incelenen propaganda posterlerinin konu ve içerik bakımından birbirine benzediği görülmüştür. Çalışmada amaçlı örneklem metodu kullanılarak yapılan analizde Tayvan konulu Çin propaganda posterlerinin altı başlık altında toplandığı ortaya çıkarılmıştır. Çalışmada belirlenen altı başlığı en iyi şekilde yansıtacağı düşünülen altı propaganda posteri çalışmanın örneklemi olarak belirlenmiştir. Bu amaçla çalışmanın bu bölümünde "Devrim", "Esaret", "Özgürlük", "Zulüm", "Kitap" ve "Anavatan" konulu propaganda posterleri göstergebilimsel açıdan analiz edilmiştir.

\section{1. "Devrim" Konulu Propaganda Posteri}

"Devrim" konulu propaganda posteri, Mo Pu tarafından 1950 yılında yapılmıștır. Posterde düzanlam boyutunda analiz edildiğinde, posterde ellerinde ÇHC bayrakları bulunan Çin halkının Çinli askerleri limanda gemilere bindirdikleri görülmektedir. Posterdeki sunum kodları üzerinden Çin halkının mutlu olduğu yansıtılmaktadır. Limanın girişine Mao'nun resmi koyulmuş, bu nedenle limandan ayrılan askerler Mao'nun resmi altından geçerek gemilere doğru yol almaktadır. Posterde savaş gemilerinin ilerlediği, hemen üstlerinde de savaş uçaklarının havalandığı aktarılmaktadır. Posterin üstünde "Tayvan'ı devirmek için Halk Kurtuluş Ordusu'nu yollamak! Devrimci savaşı sonuna kadar yürütün!" yazılı kod bulunmaktadır. 
Resim 1. "Devrim" Konulu Propaganda Posteri

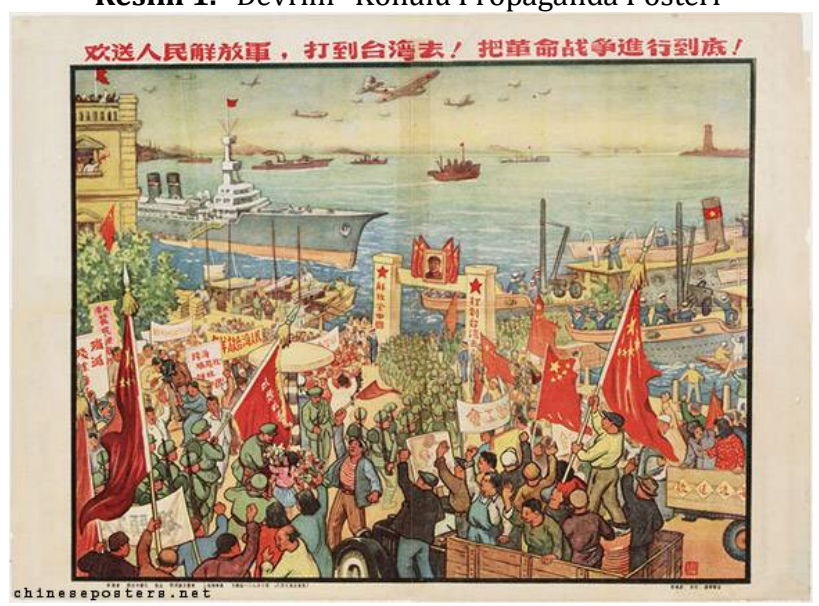

(Kaynak: IISH, 2019)

Yananlam açısından ele alındığında, posterde Çin'in Tayvan'ı işgal etmesi ve Çan Kay Şek rejimine son vermesinin hedeflendiği aktarılmaktadır. Posterde gemilere binerek ilerleyen asker görselleri, Tayvan'ı işgal etmeyi planlayan Çin ordusunun askerlerinin metonimi (temsili) olarak kullanılmaktadır. Görsel kodlar olarak kullanılan Çin bayrakları ve Mao'nun limanın girişindeki portresi ülkede Mao kültünün ve Komünizm ideolojisinin egemenliğinin vurgusunu yapmaktadır. Nitekim ÇHC'de Mao'nun mutlak liderliği üzerine yoğun bir propaganda faaliyet yürütülmekteydi (Landsberger, 1996: 196). Posterde herkesin neşeli olarak sunulması, Çin halkının Tayvan'ı ele geçirmek istediği şeklinde bir algının oluşmasına neden olmaktadır. Posterde Çin propagandası tarafından "Çin, devrimin tamamlanabilmesi için Tayvan'ı işgal etmesi gerekir" şeklinde mit inşa edilmektedir. İnşa edilen propaganda miti ile Tayvan'ın ele geçirilmesinin gerekliliği üzerinde durulmakta, devrimin tamamen ülkede etkisinin hissettirebilmesi için Çan Kay Şek'in rejiminin yıkılması gerektiği aktarılmaktadır.

Tablo 1. "Devrim" Konulu Propaganda Posteri

\begin{tabular}{|l|l|}
\hline Gösteren & Askerler ve siviller \\
\hline Gösterilen & Devrim, komünizm, işgal \\
\hline Düzanlam & Sivillerin askerleri uğurlaması \\
\hline Yananlam & Çin'in Tayvan'ı işgal etmesi ve Çan Kay Şek rejimine son vermesi \\
\hline İnşa Edilen Propaganda Miti & Tayvan ele geçirildiğinde Çin Devrimi tamamlanacaktır \\
\hline
\end{tabular}

\section{2. "Esaret" Konulu Propaganda Posteri}

"Esaret" konulu propaganda posteri Tao Mouji tarafından 1954 yılında yapılmıştır. Düzanlam açısından ele alındığında, posterde Çan Kay Şek'e bağlı bir askerin Tayvanlı bir sivili esir aldığı yansıtılmaktadır. Sunum kodları içerisinde Tayvanlı sivilin kıyafetlerinin parçalanmış olduğu aktarılmaktadır. Posterin hemen önünde bağırmakta 
olan bir kadın yer almaktadır. Posterin merkezinde ise alevler resmedilmektedir. "Posterin altında "Tayvanlı vatandaşlarımızı kurtarın!" yazılı kodu bulunmaktadır.

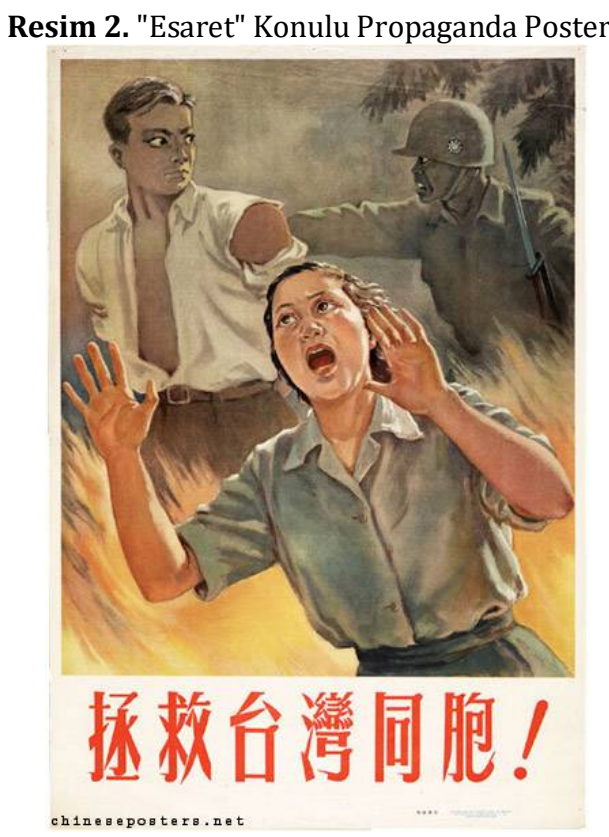

(Kaynak: IISH, 2019)

Poster yananlam boyutunda analiz edildiğinde, posterde Çan Kay Şek'in askerlerinin Tayvanlı sivillere zulmettiği iddia edilmektedir. Tayland'da Mao'nun liderliğine benzer şekilde Çan Kay Şek'in kült liderliği inşa edilmişti (Taylor, 2006. 97). ÇHC'nin propaganda faaliyetleri bu kültün yıkılmasında önemli bir rol oynamaktaydı. Posterde yer alan siviller Tayvanlı vatandaşlarının, asker ise Çan Kay Şek'e bağlı tüm askerlerin metonimi olarak kullanılmaktadır. Posterdeki görsel kodlar üzerinden Tayvanlı sivillerin Çan Kay Şek'in yönetimi altında zor günler geçirdiği ve yardıma ihtiyaç duydukları aktarılmaktadır. Çin böylece "Tayvan Ordusu, Çin halkına zulmeder" şeklindeki propaganda mitini Çin kamuoyunda hakim kılmaya çalışmaktadır. Propaganda miti sayesinde Çin'in Tayvan'a olası müdahalesinin masum sivilleri kurtarmak gibi meșru bir temele bağlanması hedeflenmektedir. Böylece Çin, Tayvan'a saldırmasının bir işgal değil, kurtarma operasyonu olarak algılanmasını amaçlamaktadır.

Tablo 2. "Esaret" Konulu Propaganda Posteri

\begin{tabular}{|l|l|}
\hline Gösteren & Çan Kay Şek'e bağlı asker ve Tayvanlı siviller \\
\hline Gösterilen & İşgal, esaret, yıkım, zulüm \\
\hline Düzanlam & $\begin{array}{l}\text { Çan Kay Şek'e bağlı askerin, Tayvanlı adamı esir alması ve yanan } \\
\text { ateșten kadının kaçması }\end{array}$ \\
\hline Yananlam & Çan Kay Şek askerlerinin Tayvanlılara zulmettiği \\
\hline İnşa Edilen Propaganda Miti & Tayvan Ordusu, Çin halkına zulmeder \\
\hline
\end{tabular}




\section{3. "Özgürlük" Konulu Propaganda Posteri}

"Özgürlük" konulu propaganda posteri Yang Han tarafından 1955 yılında yapılmıştır. Posterde düzanlam boyutunda analiz edildiğinde, posterde sol elini yumruk yapmıș, sağ eli ile de tüfeğini tutan bir ÇHC askeri resmedilmektedir. Askerin arkasından ise ÇHC ait gemilerin bir yöne doğru ilerlediği aktarılmaktadır. Posterin altında "Tayvan'ı mutlaka özgür bırakacağız" yazılı kodu bulunmaktadır.

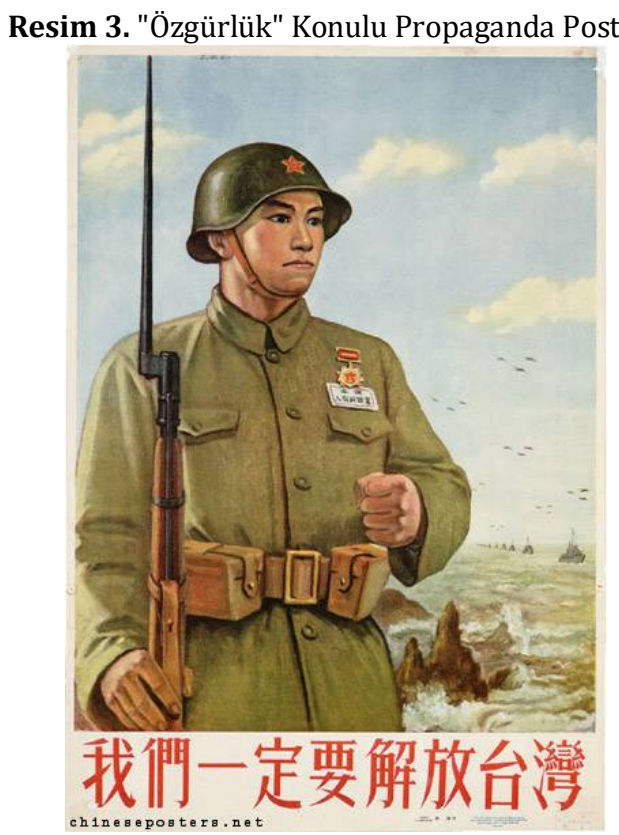

(Kaynak: IISH, 2019)

Yananlam açısından ele alındığında, posterde Çin ordusunun Tayvan'ı ele geçirmeye istekli olduğu mesajı verilmeye çalıșılmaktadır. Posterde resmedilen asker görseli, Çin ordusunun metonimi olarak kullanılmaktadır. Sunum kodları üzerinden askerin elini yumruk yapması, Çin ordusunun Tayvan'da Çan Kay Şek'in yönetiminin sürmesine karşı oldukları mesajını vermektedir. Posterin arka fonunda ilerlemekte olan Çin gemileri ise Tayvan'ı işgal etmeye hazır bekleyen Çin donanmasının metonimi olarak kullanılmaktadır. Posterde yazılı ve görsel kodlar üzerinden "Çin askerleri Tayvan'ı işgal etmek ister" propaganda mitinin inşa edilmeye çalışıldığı görülmektedir. Çin'in Tayvan'ı işgal etme düşüncesinin yalnızca Mao'nun kişisel bir isteği olmadığı, Çin ordusunun da en önemli arzularından biri olduğu aktarılmaktadır. Bu şekilde Çin'in Tayvan'a yönelik planlarının meşruluk kazanması amaçlanmaktadır. 
Tablo 3. "Özgürlük" Konulu Propaganda Posteri

\begin{tabular}{|l|l|}
\hline Gösteren & Çin askeri ve Çin donanması \\
\hline Gösterilen & Güç, işgal, saldırı \\
\hline Düzanlam & Çinli askerin, Çin donanmasının önünde durması \\
\hline Yananlam & Çin Ordusu'nun Tayvan'ı işgal etmeye hazır olması \\
\hline İnşa Edilen Propaganda Miti & Çin askerleri Tayvan'ı işgal etmek ister \\
\hline
\end{tabular}

\section{4. "Zulüm" Konulu Propaganda Posteri}

"Zulüm" konulu propaganda posteri, Hu Jinye tarafından 1955 yılında yapılmıştır. Düzanlam açısından ele alındığında, posterde karanlık bir arka fon içerisinde Çan Kay Şek'e bağlı askerlerin Tayvanlı sivilleri direklere bağladıkları aktarılmaktadır. Tayvanlı sivillerin görsel kodlar içerisinde yorgun ve bitkin oldukları yansıtılmaktadır. Posterde resmedilen Tayvanlı bir kadının üzerinde "toplama kampı" yazısı bulunan bir not bulunmaktadır. Sunum kodları içerisinde Tayvanlı kadının umutsuzca baktığı aktarılmaktadır. Posterin altında "Tayvan'ı kararlı bir şekilde özgürleştirin, Tayvanlıları sefaletinden kurtarın!" yazılı kodu bulunmaktadır.

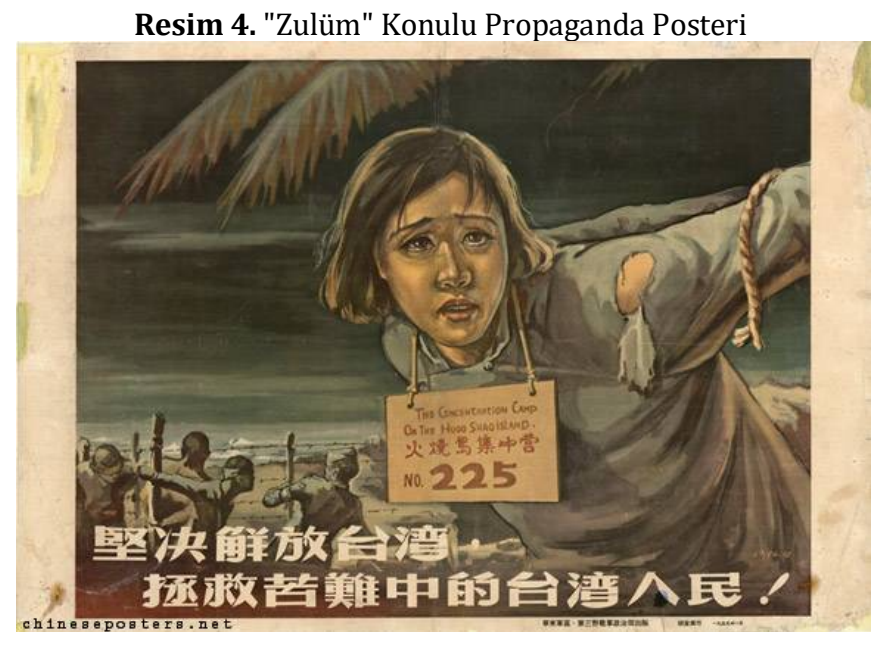

(Kaynak: IISH, 2019)

Poster yananlam boyutunda analiz edildiğinde, posterde Tayvanlı sivillerin Çan Kay Şek'in askerleri tarafından zulme maruz kaldığı mesajı verilmektedir. Posterde yer alan sivil görselleri tüm Tayvan halkın metonimi olarak kullanılmaktadır. Posterde hüzün duygularının ön plana çıkarılarak kitlelerin ikna edilmesinin amaçlandığı hüzün çekiciliği tekniğinin kullanıldığı görülmektedir. Posterdeki görsel kodlar üzerinden "Tayvan halkı Çan Kay Şek'in askerlerini ülkelerinde istemiyor" şeklinde propaganda miti inşa edilmektedir. Diğer yandan posterde yer alan yazılı kodlar üzerinden Çin ordusunun Tayvanlı sivilleri kurtarmak için harekete geçmesi gerektiğine vurgu yapılmaktadır. Bu şekilde Çin propagandası hem Tayvan'ın olası işgalini meşru göstermeye çalışmakta hem de Çin ordusunun Tayvan'ı işgali için teşvik edici bir ortam oluşturmaya çalışmaktadır. 
Tablo 4. "Zulüm" Konulu Propaganda Posteri

\begin{tabular}{|l|l|}
\hline Gösteren & Çan Kay Şek'in askerleri ve Tayvanlı siviller \\
\hline Gösterilen & Zulüm, esaret, işgal \\
\hline Düzanlam & Tayvanlı sivillerin iplerle bağlanması \\
\hline Yananlam & Tayvan halkı Çan Kay Şek'in ordusundan zulüm görmektedir \\
\hline İnşa Edilen Propaganda Miti & Tayvan halkı Çan Kay Şek'in askerlerini ülkelerinde istemiyor \\
\hline
\end{tabular}

\section{5. "Kitap" Konulu Propaganda Posteri}

"Kitap" konulu propaganda posteri, Çin hava kuvvetleri tarafından 1971 yılında yapılmıștır. Düzanlam boyutunda analiz edildiğinde, posterde ÇHC ordusu ve sivillerinin ellerinde silahlar ile bir yöne doğru bakmakta olduğu aktarılmaktadır. Posterde yer alan kişilerden birinin elinde Mao'nun "Kırmızı Kitap"ı olduğu görülmektedir. Görsel kodlar içerisinde sivil ve askerlerin ellerindeki kızıl bayrakları dalgalandırdıkları aktarılmaktadır. Posterin altında "Tayvan'ı mutlaka özgürleștireceğiz!" yazılı kodu kullanılmaktadır.

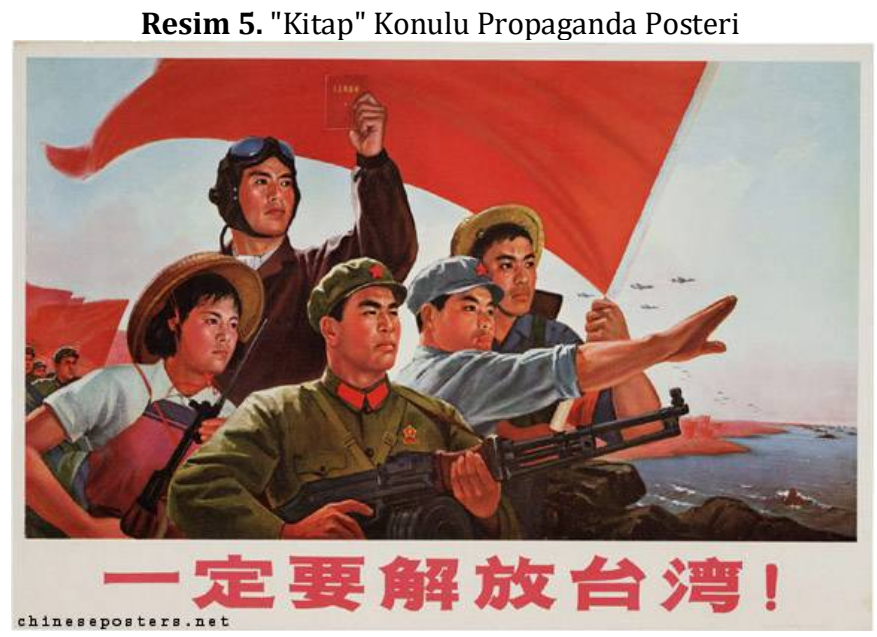

(Kaynak: IISH, 2019)

Yananlam açısından ele alındığında, posterde hem Çin halkının hem de Çin ordusunun Tayvan'ı işgal etmek istedikleri mesajı verilmeye çalışılmaktadır. Posterde resmedilen kişiler doğrudan ÇHC'nin tümünün metonimi olarak kullanılmıştır. Posterdeki görsel kodlarda kızıl bayrakların olması Komünizm vurgusunun ön plana çıkarılmasını sağlamaktadır. Çin propagandası Mao'nun kült liderlik propagandasında önemli rol üstlenmekteydi (Leese, 2011: 38). Bu açıdan Mao'nun Kırmızı Kitap'ının gösterilmesi doğrudan posterde Mao'nun kült lider propagandasının yapılmasına neden olmaktadır. Böylece Mao'nun ülkedeki egemen figür olduğu aktarılmakta aynı zamanda Çin halkının sonuna kadar Mao için savaşacakları mesajı verilmektedir. Posterde çalışma kapsamında incelenen bazı posterlerde olduğu gibi "Çin halkı Tayvan'ı işgal etmek istemektedir" 
propaganda miti inşa edilmeye çalışılmaktadır. Böylece Çin propagandası, Çin İç Savaşı'nın sonlanması üzerinden geçen zamana karşın hala Çin halkının Tayvan'daki Çan Kay Şek rejimini devirmeye istekli olduğunu aktarmaktadır.

Tablo 5. "Kitap" Konulu Propaganda Posteri

\begin{tabular}{|l|l|}
\hline Gösteren & Çin halkı \\
\hline Gösterilen & İşgal, saldırı, komünizm \\
\hline Düzanlam & $\begin{array}{l}\text { Çin halkının kızıl bayrakları ve Mao'nun Kırmızı Kitap'ını } \\
\text { taşımaları }\end{array}$ \\
\hline Yananlam & $\begin{array}{l}\text { Çin halkı Mao'ya sadakat ile bağlı olduğu, Mao'nun } \\
\text { öğretileri doğrultusunda hareket ettikleri }\end{array}$ \\
\hline İnşa Edilen Propaganda Miti & Çin halkı Tayvan'ı işgal etmek istemektedir \\
\hline
\end{tabular}

\section{6. "Anavatan" Konulu Propaganda Posteri}

"Anavatan" konulu propaganda posteri, Chen Rupeng tarafindan 1976 yılında yapılmıştır. Düzanlam açısından ele alındığında, posterde Çinli sivillerin kayıkla bir yöne doğru ilerledikleri aktarılmaktadır. Görsel kodlar içerisinde Çinli sivillerin denize Mao'nun "Kırmızı Kitap"ını attıkları görülmektedir. Bu kitap Mao'nun fikirlerini yansıtan ideolojik bir kitaptır (Priestland, 2017: 282). Kayıktaki herkesin mutlu olduğu ve kayığın çevresinde balonların bulunduğu yansıtılmaktadır. Posterde "Anavatanın sevgi dolu ilgisi" yazılı kodu bulunmaktadır.

\section{Resim 6. "Anavatan" Konulu Propaganda Posteri}

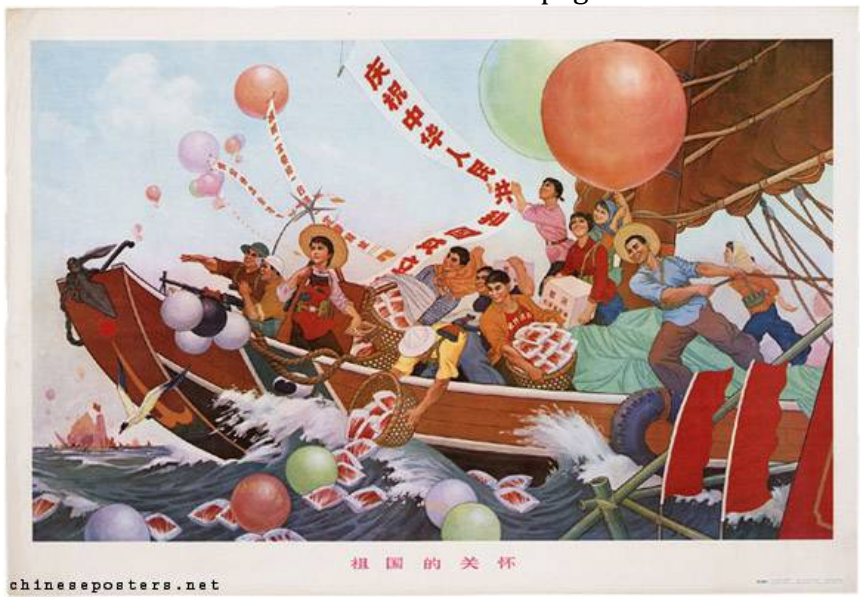

(Kaynak: IISH, 2019)

Posterde yananlam boyutunda analiz edildiğinde, posterde Çin halkının barışçıl yollarla Tayvan'daki Çan Kay Şek yönetimini sonlandırmaya çalıștığı ortaya konulmaktadır. Mao'nun kült liderliği pek çok farklı şekilde ÇHC'de sunulmaktaydı (Lago, 1999: 49). Posterde de Mao'nun kült liderliğinin bir yansıması bulunmaktadır. Posterde resmedilen kişiler yine Çin'in tamamının metonimi olarak kullanılmaktadır. Posterdeki 
görsel kodlarda Mao'nun Kırmızı Kitap'ının denize atılması ile kitapların Tayvan kıyısına vurması ve Tayvanlıların Mao'nun öğretilerini öğrenerek Çan Kay Şek'in kurduğu rejime karşı ayaklanacakları ifade edilmektedir. Posterde ütopik olarak tasvir edilen durum, Çin propagandasının Çin'in Tayvan'ı ele geçirme planlarının en yumuşatılmış sunumlarından biri olarak yansitılmaktadır. Bu nedenle posterde "Çin halkı, Tayvan'ın Mao'nun öğretileri doğrultusunda yönetilmesini istemektedir" şeklinde propaganda mitinin inşa edilmesinin amaçlandığı görülmektedir. Bu şekilde Çin propagandası Tayvan'ın Çan Kay Şek'in kurduğu rejim altında yaşamasını istemediği mesajını vermekte ve Çin-Tayvan düşmanlığını yumuşak bir zeminde de olsa sürdürmeye devam etmeye çalışmaktadır.

Tablo 6. "Anavatan" Konulu Propaganda Posteri

\begin{tabular}{|l|l|}
\hline Gösteren & Çin halkı \\
\hline Gösterilen & Sevgi, mutluluk, sevinç, yardım \\
\hline Düzanlam & Çin halkının kayığın üzerinden Mao'nun Kırmızı Kitap'larını atması \\
\hline Yananlam & $\begin{array}{l}\text { Çin halkı Tayvan'da Komünizm ideolojisinin hâkim olması, Çan Kay Şek'in } \\
\text { yönetiminin son bulması için çalışmaktadır. }\end{array}$ \\
\hline $\begin{array}{l}\text { İnşa Edilen } \\
\text { Propaganda Miti }\end{array}$ & $\begin{array}{l}\text { Çin halkı, Tayvan'ın Mao'nun öğretileri doğrultusunda yönetilmesini } \\
\text { istemektedir. }\end{array}$ \\
\hline
\end{tabular}

\section{Sonuç}

Çalışma kapsamında incelenen Çin propaganda posterlerinde Çin'in Tayvan'a doğrudan nefret söylemi inşa etmeye çalıștığı görülmüştür. Bu amaçla posterdeki görsel kodlar üzerinden Tayvan askerlerine yönelik barbar, cani, zalim gibi algılar oluşturulmaya çalıșılmıştır. Çin propagandası, Tayvan'a karşı posterler üzerinden; "Tayvan ele geçirildiğinde Çin Devrimi tamamlanacaktır", "Tayvan Ordusu, Çin halkına zulmeder", "Çin askerleri Tayvan'ı işgal etmek ister", "Tayvan halkı Çan Kay Şek'in askerlerini ülkelerinde istemiyor", "Çin halkı Tayvan'ı işgal etmek istemektedir" ve "Çin halkı, Tayvan'ın Mao'nun öğretileri doğrultusunda yönetilmesini istemektedir" şeklinde propaganda mitlerini inşa etmeye çalışmaktadır. İnşa edilmeye çalışılan tüm propaganda mitlerinde Çin'in Tayvan'ı işgal etmesinin meşru bir zemine dayandırılmaya çalışıldığı görülmektedir. Nitekim posterlerde Tayvan'ın Çin'de Mao yönetimi tarafından gerçekleștirilen devrime karşı olduğu vurgusu yapılmakta, devrimin gelecekte tehlikeye girmemesi için Tayvan'ın ortadan kaldırılması gerektiği aktarılmaktadır. Benzer şekilde Tayvan'a müdahalede bulunulmasını Çin halkının çok istediği mesajı verilmiş, bu şekilde Tayvan'ın işgal edilmesinin yalnızca Mao'nun isteği üzerine gerçekleşmeyeceği vurgulanmıștır. Diğer yandan posterlerde Tayvan halkının Çan Kay Șek yönetimi altında zulme uğradığı iddia edilerek, Çin halkının Tayvanlı sivilleri özgürleştirmek için harekete geçmesi gerektiği mesajı verilmiştir. Bu aşamada Komünizm ideolojisinin ve Mao'nun kült liderliğine yönelik yüceltici mesajlara yer verilmiştir. Böylece Çinin olduğu gibi Tayvan'ın da Komünizm ideolojisi altında, Mao'nun liderliğinde yönetilebilmesi için Çan Kay Şek'in kurduğu rejimin mutlaka devrilmesi gerektiği vurgulanmıştır.

Elde edilen bulgularda Mao iktidarı döneminde kullanılan propaganda posterlerinde Çin-Tayvan arasındaki düşmanlığın canlı tutulmasına çalıșıldığı görülmektedir. Propaganda posterlerinde gelecekte Çin'in Tayvan'ı ele geçireceği vaat edilerek, Çin halkının Tayvanlı sivilleri Çan Kay Şek'in despot yönetiminden kurtaracakları iddia edilmiştir. Böylece posterlerdeki temel vaat, Tayvanlıların uğradıkları iddia edilen zulümden kurtarılması olmuştur. Çalışma kapsamında incelenen son propaganda posteri haricindeki tüm posterlerde Çin'in Tayvan'a doğrudan 
müdahalede bulunması gerektiği aktarılmıştır. Son posterde ise Tayvan halkının Mao'nun öğretilerini öğrendiği takdirde mevcut rejimi değiștirebileceği mesajı verilmiștir. Bu amaçla Tayvan yönetimi sert bir dille eleştirilirken, Çin yönetimi ise özgürlükçü tutumu ile yüceltilmiștir. Posterlerde Tayvan'a karşı yürütülen tutum, Mao dönemindeki ÇinTayvan ilișkilerindeki gerilimin bir yansıması olarak ortaya çıkmıștır. Mao, posterler üzerinden Barthes'ın belirttiği yapay mit olgusunu başarıyla oluşturarak, Çin'de kimin dost kimi düşman olduğunu ve Çin'in gelecekte Tayvan'a karşı nasıl bir yol izleyeceğini inşa etmeye çalışmıştır.

Çalışmada Çin propaganda posterleri üzerinden yapılan analizlerle Mao dönemindeki Çin-Tayvan ilişkilerine ışık tutulması amaçlanmıştır. Gelecek çalışmaların Tayvan'ın Çin'e yönelik propaganda faaliyetlerini Tayvan lideri Çan Kay Şek dönemi özelinde mevcut çalışmada elde edilen bulgular ile karşılaștırmalı olarak analiz etmesinin gerek propaganda gerekse uluslararası ilișkiler alanına katkı sağlayacağı düşünülmektedir.

\section{KAYNAKÇA}

ADSHEAD, S. A. M. (200). China in World History. New York: Palgrave.

BARTHES, R. (2014). Çağdaş Söylenler. Çev., Tahsin Yücel. 4. Baskı. İstanbul:

Metis Yayınları.

BARTHES, R. (2016a). Göstergebilimsel Serüven. Çev., Mehmet Rifat, Sema

Rifat. 8. Baskı. İstanbul: Yapı Kredi Yayınları.

BARTHES, R. (2016b). S/Z. Çev., Sündüz Öztürk Kasar. İstanbul: Sel Yayıncllık.

BARTHES, R. (2017). Görüntünün Retoriği, Sanat ve Müzik. Çev., Ayşenaz Koș.

Ömer Albayrak. 2. Baskı. İstanbul, Yapı Kredi Yayınları.

BRADY, A. M., \& JUNTAO, W. (2009). "China's Strengthened New Order and

the Role of Propaganda". Journal of Contemporary China, 18(62), 767-788.

BROOMAN, J. (1998). China Since 1900. New York: Longman.

CAO, D. \& YANJING, S. (2011). China's History. Singapore: Cengage Learning

Asia.

CARTER, J. (2016). "The Rise of Nationalism and Revolutionary Parties".

Jeffrey N. Wasserstrom (eds.), Modern China, New York: Oxford University Press, pp. 118-150.

CHAI, W. (2002). "The Taiwan Factor in US-China Relations: An

Interpretation". Asian Affairs: An American Review, 29(3), 131-147.

CHEEK, T. (2008). Mao Zedong and China's Revolutions. New York: Palgrave.

CHEN, T. M. (2003). "Propagating the Propaganda Film: The Meaning of Film

in Chinese Communist Party Writings, 1949-1965". Modern Chinese Literature and Culture, 15(2), 154-193.

CHEN, X. (2016). "Staging Chinese Revolution: Theater, Film, and the

Afterlives of Propaganda". The United States: Columbia University Press.

ÇAKI, C. (2018a). "Ermenistan Sovyet Sosyalist Cumhuriyeti'nde Joseph Stalin

Döneminde Kullanılan Sovyet Propaganda Posterleri Üzerine İnceleme". Ermeni

Araștırmaları, (61), 271-296.

ÇAKI, C. (2018b). "İran-Irak Savaşı'nda Kullanılan İran Propaganda

Posterlerinin Göstergebilimsel Analizi". Iran Çalışmaları Dergisi, 2(1), 11-39.

ÇAKI, C. (2018c). "Adolf Hitler'in Kült Lider İnşasında Kullanılan Propaganda

Posterlerinin Göstergebilimsel Analizi". Abant Kültürel Araştırmalar Dergisi, 3(6), 2438. 
ÇETIN, M., ÇAKI, C., \& GAZI, M. A. (2018). "The Examination of The Anti-Usa Propaganda Posters in The Iran Revolution According to Claude Lévi-Strauss'binary Opposition". Uluslararası Sosyal Bilimler Dergisi, 1(3), 31-51.

DE SAUSSURE, F. (2014) Genel Dilbilim Yazıları. Çev., Savaş Kılıç, İstanbul: İthaki Yayınları.

EDNEY, K. (2014). The Globalization of Chinese Propaganda: International Power and Domestic Political Cohesion. The United Kingdom: Springer.

ERÖKTEM, M. (2018). “Tayvan Gözlemleri”. A. MerthanDündar (eds.), Tayvan Studies in Turkey (History, Economy and International Relations), Ankara: Ankara Üniversitesi Yayınları No: 616 Asya-Pasifik Çalıșmaları Uygulama ve Araştırma Merkezi, pp. 201-220

GAY, K. (2008). Mao Zedong's China. Mineapolis: Twenty First Century Books.

GAZİ, M. A., ÇAKI, C., \& GÜLADA, M. O. (2018a). "İkinci Dünya Savaşı'nda Sovyet Kült Lider Propagandasında Vladimir Lenin ve Joseph Stalin'in Sunumu". Dördüncü Kuvvet Uluslararası Hakemli Dergi, 1(2), 25-42.

GAZİ, M. A., ÇAKI, C., \& GÜLADA, M. O. (2018b). "İspanya 2000 Partisi'nin Göçmen Karşıtı Propaganda Faaliyetleri Üzerine İnceleme". Ankara Uluslararası Sosyal Bilimler Dergisi, 1(2), 11-22.

IISH (2019). "Çin Propaganda Posterleri", https://search. social history. org/Search /Results? \&format \%3A\%22 Visual+ documents \%22\&lookfor= China+ poster+ Mao+Tse-Tung, (Erişim Tarihi: 21.03.2019).

JOHNSON, M. D. (2012). "Propaganda and Censorship in Chinese Cinema". A Companion to Chinese Cinema, 153-78.

KAN, S. A. (2014). "China/Taiwan: Evolution of the One China Policy Key Statements from Washington, Beijing, and Taipei", Congressional Research Service, CRS Report.

LAGO, F. D. (1999). "Personal Mao: Reshaping an Icon in Contemporary Chinese Art". Art Journal, 58(2), 46-59.

LANDSBERGER, S. R. (1996). "Mao as the Kitchen God: Religious Aspects of the Mao Cult during the Cultural Revolution". China Information, 11(2-3), 196-214. LEESE, D. (2011). Mao Cult: Rhetoric and Ritual in China's Cultural Revolution. The United Kingdom: Cambridge University Press.

LING, L. H., HWANG, C. C., \& CHEN, B. (2009). Subaltern Straits:'Exit','Voice', and 'Loyalty'in the United States-China-Taiwan Relations. International Relations of the Asia-Pacific, 10(1), 33-59.

LYNCH, M. (2016). China: From Empire to People's Republic: 1900-49. İkinci Baskı. Londra: Hodder Education. Yayınlarl.

MCMAHON, J. R. (2013). Soğuk Savaş, Çev. Sinem Gül, Ankara: Dost Kültür

MORTON, W. S., \& Lewis, C. M. (2005). China: Its History and Culture. New

York: McGraw-Hill.

States: Gale. PONG, D. (2009). Encyclopedia of Modern China, Volume 1. (eds.), United POWELL, P., \& WONG, J. (1997). "Propaganda Posters from the Chinese Cultural Revolution". The Historian, 59(4), 777-793. PRIESTLAND, D. (2017). Kızıl Bayrak Bir Komünizm Tarihi, Çev. Ali Çakıroğlu, Egemen Yılgür. İstanbul: İletişim Yayınları. REN WU, R. (2004). "Fragment of Empires: The Peripheral Formation of Taiwanese Nationalism”. Social Science Japan 30: 16-18. ROPP, P. S. (2010). China in World History. New York: Oxford University Press. 
SPENCE, J. D: (2012). The Search For Modern China. New York: W. W. Norton \& Company.

TANYERİ MAZICI, E., \& ÇAKI, C. (2018). "Adolf Hitler'in Korku Çekiciliği Bağlamında Kamu Spotu Reklamlarında Kullanımı". Erciyes İletişim Dergisi, 5(3), 290-306.

TAYLOR, J. E. (2006). "The Production of the Chiang Kai-Shek Personality Cult, 1929-1975". The China Quarterly, 185, 96-110.

WEBER, I. (2002). "Reconfiguring Chinese Propaganda and Control Modalities: A Case Study of Shanghai's Television System". Journal of Contemporary China, 11(30), 53-75.

YALVAÇ, F. (2018). “Tayvan ve Uzakdoğu'da Hegemonik Liderlik Mücadelesi”. A. Merthan Dündar (eds.), Tayvan Studies in Turkey (History, Economy and International Relations), Ankara: Ankara Üniversitesi Yayınları No: 616 Asya-Pasifik Çalışmaları Uygulama ve Araștırma Merkezi, pp. 201-220.

ZHANG, J., \& CAMERON, G. T. (2004). "The Structural Transformation of China's Propaganda: An Ellulian Perspective". Journal of Communication Management, 8(3), 307-321.

\section{Summary}

The basis of the Chinese propaganda against Taiwan constituted the persuading of the Chinese people influenced by the nationalist rhetoric of the Kuomintang and the demonstration of the Chiang Kai-Shek administration as an enemy in the awakening of national consciousness. For this purpose, posters, one of the most effective mass media tools of the period, were effectively used by anti-Taiwan Chinese propaganda. In the study, Chinese propaganda posters prepared against Taiwan were examined using semiotic analysis method. The main aim of this study is to give information on the presentation the relations between China and Taiwan through posters used by China propaganda during the Mao's regime. Thus, it was aimed to determine the role of Chinese propaganda in the Mao's regime in shaping the current state of China-Taiwan relations. The study is important in terms of the fact that there is no study on the role of propaganda activities in the Chinese-Taiwan relations in the national studies, giving an example about the use of propaganda in international relations and also providing information about the anti-Taiwan Chinese propaganda in the Mao's regime.

During the Mao's regime, all the propaganda posters prepared against Taiwan constitute the universe of the study. On the other hand, due to the difficulty of accessing all the propaganda posters within the scope of the study, the analysis was conducted on the six propaganda posters determined using the purposeful sampling method. Within the scope of the study, the examining of only the six Chinese propaganda posters and making generalizations within the scope of the findings are the main limitations of the study. In this study, the semiotic analysis method in qualitative research methods was used. The propaganda posters used by Chinese propaganda were analyzed in the light of the semiotical understanding of the French linguist Roland Barthes.

In Chinese propaganda posters examined within the scope of study, it was showed that China directly tried to construct hate speech to Taiwan. For this purpose, it was tried to form perceptions such as barbarian, murderous and cruel against Taiwanese soldiers via visual codes in the poster. China propaganda constructed myths such as; "China must invade Taiwan for the completion of the revolution", "Taiwan Army persecutes the Chinese people", "Chinese soldiers want to occupy Taiwan", "the Taiwanese people do not want the soldiers of Chiang Kai Shek", "Chinese people want to occupy Taiwan", and "the Chinese people want 
Taiwan to be governed with Mao's teachings" against Taiwan through posters. It was seen that all of the propaganda myths that were tried to be built were based on a legitimate ground of China's invasion of Taiwan. As a matter of fact, the posters emphasized that Taiwan was opposed to the revolution carried out by Mao in China and it was stated that Taiwan should be invaded in order to strengthen the revolution in the future. Similarly, the message that the Chinese people very much wanted to intervene in Taiwan was given by emphasizing that the invasion of Taiwan would not happen only at Mao's request. On the other hand, the posters claimed that the Taiwanese people were persecuted under the Chiang Kai-Shek's regime and that the Chinese people should take action to liberate Taiwanese civilians. At this stage, exalting messages of Communism ideology and Mao's cult leadership were given. Thus, it was emphasized that the regime established by Chiang KaiShek should be overthrown in order to manage Taiwan under the Communism ideology and Mao's leadership.

In the findings, it was seen that the propaganda posters used during the Mao'regime were kept alive the enmity between China and Taiwan. Propaganda posters alleged that China would invade Taiwan in the future and the Chinese people would save Taiwanese civilians from the despotic regime of Chiang Kai Shek. Thus, the basic promise in the posters was to free the Taiwanese from the alleged persecution. All posters, except for the final propaganda poster, which was examined within the scope of the study, stated that China should directly intervene in Taiwan. In the last poster, the message that the Taiwanese people could change the despotic regime if they learnt Mao's teachings was given. For this purpose, the Taiwan administration was criticized harshly, while the Chinese government was exalted with its libertarian attitude. The attitude against Taiwan in the posters appeared as a reflection of the tension in Chinese-Taiwan relations during the Mao's reign. Mao successfully made the phenomenon of artifical myth by Barthes on posters and tried to build up how China would proceed against Taiwan in the future. 